\title{
Analysing the essential proteins set of Plasmodium falciparum PF3D7 for novel drug targets identification against malaria
}

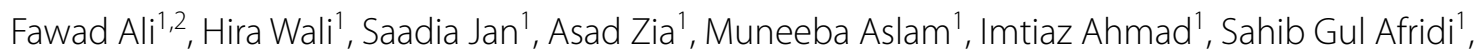
Sulaiman Shams ${ }^{1}$ and Asifullah Khan ${ }^{1 *}$ (1)

\begin{abstract}
Background: Plasmodium falciparum is an obligate intracellular parasite of humans that causes malaria. Falciparum malaria is a major public health threat to human life responsible for high mortality. Currently, the risk of multi-drug resistance of $P$. falciparum is rapidly increasing. There is a need to address new anti-malarial therapeutics strategies to combat the drug-resistance threat.
\end{abstract}

Methods: The P. falciparum essential proteins were retrieved from the recently published studies. These proteins were initially scanned against human host and its gut microbiome proteome sets by comparative proteomics analyses. The human host non-homologs essential proteins of $P$. falciparum were additionally analysed for druggability potential via in silico methods to possibly identify novel therapeutic targets. Finally, the PfAp4AH target was prioritized for pharmacophore modelling based virtual screening and molecular docking analyses to identify potent inhibitors from drug-like compounds databases.

Results: The analyses identified six P. falciparum essential and human host non-homolog proteins that follow the key druggability features. These druggable targets have not been catalogued so far in the Drugbank repository. These prioritized proteins seem novel and promising drug targets against $P$. falciparum due to their key protein-protein interactions features in pathogen-specific biological pathways and to hold appropriate drug-like molecule binding pockets. The pharmacophore features based virtual screening of Pharmit resource predicted a lead compound i.e. MolPort-045-917-542 as a promising inhibitor of PfAp4AH among prioritized targets.

Conclusion: The prioritized protein targets may worthy to test in malarial drug discovery programme to overcome the anti-malarial resistance issues. The in-vitro and in-vivo studies might be promising for additional validation of these prioritized lists of drug targets against malaria.

Keywords: Plasmodium falciparum, Malaria, Comparative proteomics, Anti-malarial therapeutics, Pharmacophore modelling

*Correspondence: asif@awkum.edu.pk; asifullah111@gmail.com ${ }^{1}$ Department of Biochemistry, Abdul Wali Khan University Mardan, Mardan 23200, Pakistan

Full list of author information is available at the end of the article

\section{Background}

Malaria is a life-threatening infectious disease caused by parasitic protozoan plasmodium. It is a vector borne disease, transmitted to humans through the bite of infected carrier female Anopheles mosquitoes. Among five parasite species that cause malaria in humans, two species, Plasmodium falciparum and Plasmodium vivax, have original author(s) and the source, provide a link to the Creative Commons licence, and indicate if changes were made. The images or other third party material in this article are included in the article's Creative Commons licence, unless indicated otherwise in a credit line to the material. If material is not included in the article's Creative Commons licence and your intended use is not permitted by statutory regulation or exceeds the permitted use, you will need to obtain permission directly from the copyright holder. To view a copy of this licence, visit http://creativecommons.org/licenses/by/4.0/. The Creative Commons Public Domain Dedication waiver (http://creativeco mmons.org/publicdomain/zero/1.0/) applies to the data made available in this article, unless otherwise stated in a credit line to the data. 
the greatest threat to human life [1]. The P. falciparum, a unicellular protozoan, belongs to the family Plasmodiidae and lies in the phylum Apicomplexa [2]. Plasmodium falciparum alone is responsible for almost all malariainflicted deaths in sub-Saharan Africa, with the continent bearing over $90 \%$ of the global $P$. falciparum burden [3-5]. Asia is second to Africa in terms of malaria prevalence. In 2019, the World Health Organization (WHO) estimated 229 million malaria cases and about 409,000 deaths due to malaria worldwide every year [6]. More than $85 \%$ of confirmed recorded cases and deaths in Asia occurred in India, Indonesia, Myanmar, and Pakistan [7].

The $P$. falciparum resistance is reported to many approved anti-malarial drugs, including the chloroquine and artemisinin [8]. Resistance to chloroquine was first observed in Thailand in 1957 and the Colombian-Venezuelan border in 1959 [9]. Drug resistance had spread across sub-Saharan Africa by 1988, and today chloroquine is no longer effective in almost all parts of the world [10]. Specific polymorphisms in the P. falciparum chloroquine resistance transporter (PfCRT) are reported in association with chloroquine resistance [11]. Likewise, the artemisinin resistance was first documented in 2008 in the Thailand-Cambodia border regions $[12,13]$. The artemisinin resistance associated with delayed parasitic clearance after three days of artemisinin monotherapy. Several studies have reported that artemisinin resistance emerged due to a polymorphism in the $p f k 13$ gene [14, 15].

The indispensable proteins of $P$. falciparum recently explored from well experimental approaches in some studies. These repositories are promising to identify suitable targets to overcome the drug-resistant $P$. falciparum infection [16, 17]. Zhang et al. [16] experimentally analysed 5399 genes and identified 2680 as essential for optimal growth of $P$. falciparum during asexual blood stages. These essential genes coding the $P$. falciparum vital proteins, including drug targets and potential vaccine candidates. Besides, there are over 1,000 of Plasmodiumconserved essential genes with unknown biological functions so far. In the current study, these essential proteins were retrieved from the two recently published studies and assessed for druggable potential based on comparative proteomics, protein-protein interactions and druglike molecules binding potential.

\section{Methods}

The methodological layout of the current study is depicted in Fig. 1.

\section{Retrieval of non-paralogous essential proteins}

The essential proteins of $P$. falciparum strain 3D7 were retrieved from two recently published studies $[16,17]$.
The paralogous proteins were removed by CD-HIT clustering analysis with $\geq 80 \%$ sequence similarity cutoff [18].

\section{Human host non-homologous and virulent proteins identification}

The P. falciparum essential proteins non-homolog to human host proteome were identified by comparative sequence analyses via BLASTp tool [19]. The threshold values of $\leq 35 \%$ query coverage and sequence identity were set during this analysis [20]. The proteins having significant similarity with human proteome were discarded and the remaining non-homologs were shortlisted for further analysis. The non-homology search against human gut microbiota proteins sequences was also carried out with a threshold cutoff, i.e. E value $\geq 0.001$ [21, 22]. The Victors database was screened for $P$. falciparum 3D7 virulent proteins annotation. The Victors database contains 5304 virulent proteins data from various parasites including $P$. falciparum [23].

\section{Drugbank database scanning}

The shortlisted essential proteins of $P$. falciparum from above analyses were scanned against the Drugbank database to identify novel drug targets with $\leq 60 \%$ query coverage and percent identity threshold of BLASTp [24].

\section{Structure homologs search}

The proteins data bank (PDB) was screened to identify the homologous 3D structures of pathogenic proteins [25]. The pathogen proteins were BLAST against the entire PDB database entries $[22,26]$. The pathogen sequences having $\geq 60 \%$ homology were modeled with Swiss Model [27] and verified by ERRAT [28] and RAMPAGE [29].

\section{Druggablity analyses}

The prioritized list of essential proteins shortlisted from above analyses were tested for druggability potential. The drug-like molecules binding pockets of the targets were identified by PockDrug-server [30]. The subcellular localization was performed with CELLO v.2.5 [31]. The molecular weight of the proteins were also accounted during their druggability assessment [32]. The PPI analysis was performed by the STRING database and the Hub proteins were identified based on node degree $(K \geq 5)$ that represents the number of interactions [33].

\section{Pharmacophore based virtual screening}

Pharmit server was employed to design a pharmacophore model using the 3D structure of $P$. falciparum diadenosine tetraphosphate hydrolase (PfAp4AH) enzyme (PDB ID 5CFJ) [43]. Pharmit provides interactive screening 


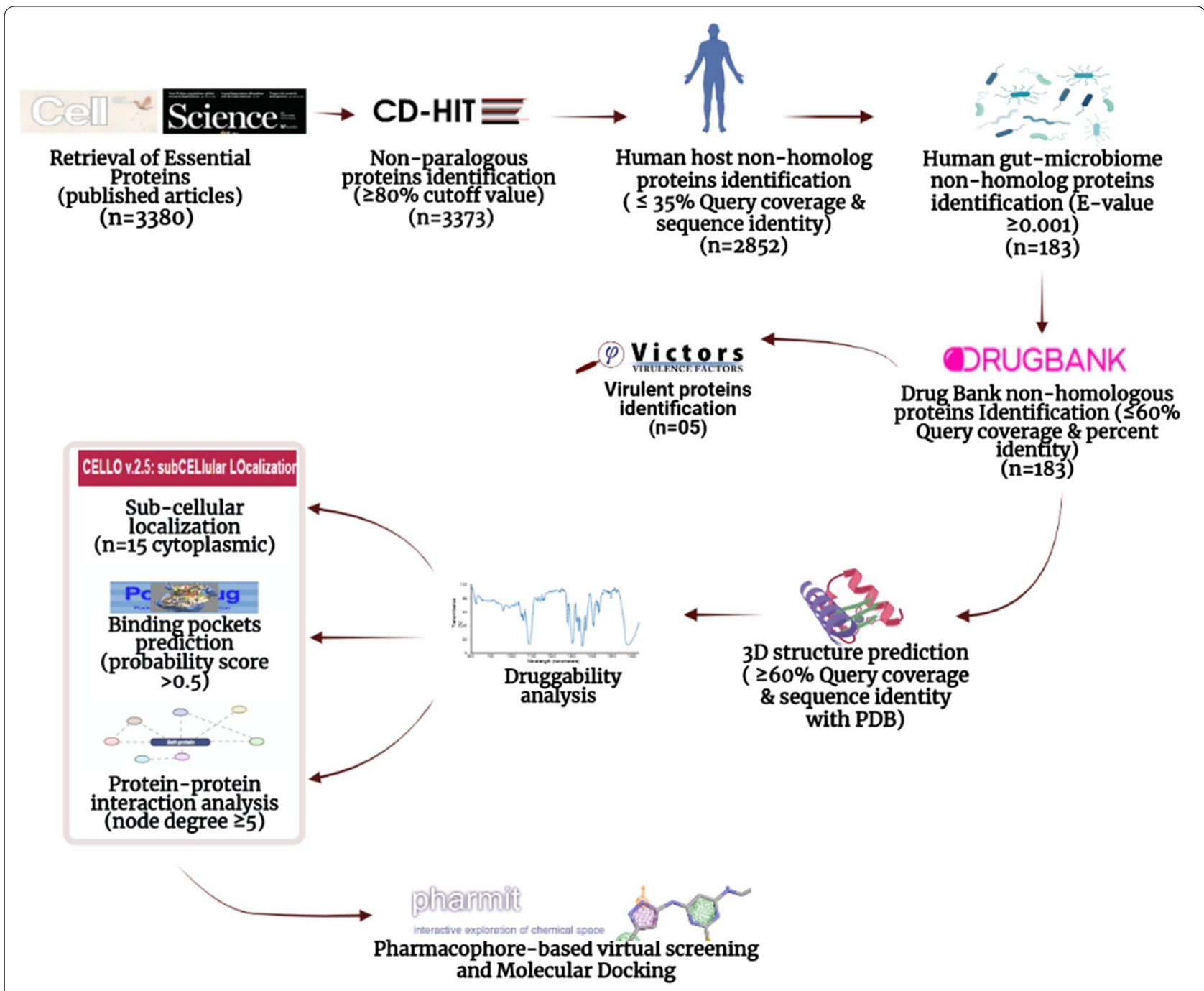

Created in BioRender.com bio

Fig. 1 The stepwise workflow adopted for novel anti-malarial drug targets identification

of millions of chemical compounds from built-in databases, i.e. Molprot, ChEMBL, ZINC, and PubChem. The Pharmit server is based on a pharmacophore model using AutoDock Vina scoring function [34]. The pharmacophore model was built using seven features, i.e. two hydrogen donors, two hydrogen acceptors, two hydrophobic features, and one aromatic feature. The screening results were then minimized to a significant level based on Pharmit scoring and RMSD values to obtain the best possible inhibitors out of millions of drug-like compounds. The top ten hits identified based on Pharmit screening were then docked using the CB-Dock tool to verify the ligand-binding sites [35]. Discovery studio was used for protein-ligand interaction visualization [36].

\section{Results}

Subtractive proteomic analyses

Essential genes perform key cellular functions for the survival of pathogens [37]. The P. falciparum strain 3D7 essential genes information were obtained from the recently published articles [16, 17] and total 3380 essential proteins were identified. These proteins 
sequences were retrieved from Uniprot. Seven paralogous protein sequences were excluded by CD-HIT analysis and the remaining 3373 sequences were considered for downstream analysis (Additional file 1: Table S1). The non-paralogous protein sequences were subjected to BLASTp against human proteome as well as human gut microbiome proteome data with threshold parameters. The gut flora is helpful to the host in many ways like vitamins biosynthesis and absorption of short chain-fatty acids [38]. The unintended inhibition of gut microbe leads to a decrease in gut flora and colonization of pathogenic bacteria in the host gut [39]. The comparative sequence analysis based screening (see, methodology section) against human proteome identified total 2852 P. falciparum proteins non-homolog to human host. Further screening of these P. falciparum essential and human host non-homolog proteins against human gut microbiome proteins database identified 2669 homologs and 183 non-homologs proteins (Fig. 1; Additional file 2: Table S2; Additional file 3: Table S3). The five among these 183 were annotated as $P$. falciparum 3D7 virulent proteins during screening of Victors database (Table 1). The 183 P. falciparum essential proteins identified as human as well as human gut proteome non-homologs were prioritized for downstream analyses. The homology screening of these 183 proteins based on set threshold against Drugbank repository inferred no homology with already reported drug targets deposited in drugbank database. However, 38 established anti-malarial targets from Alexander et al. [77] (Additional file 4: Table S4) were additionally catalogued to check the recovery of previously reported targets in current study. Among approved anti-malarial targets, the $P$. falciparum 2-C-methyl-D-erythritol 4-phosphate cytidylyltransferase and $P$. falciparum subtilisin-like protease-1 were listed within the 183 prioritized targets (Additional file 2: Table S2). However, when the cutoff criteria was relaxed to $35 \%$ sequence identity and $35 \%$ query coverage to screen the human gut microbiome database, then additional 16 already approved anti-malarial targets are recovered (Additional file 4: Table S4). The recovery of these established anti-malarial targets somehow validates the strategy been acquired in current study.

\section{Druggability analyses}

The Drugbank non-homologous proteins were prioritized for downstream druggability analyses. The subcellular localization is one of the key aspect of druggability and the cytoplasmic proteins are considered as suitable drug targets $[40,41]$. The 15 P. falciparum proteins among shortlisted prioritized targets were annotated as cytoplasmic proteins. The proteins 3D structures identified by Swiss model were validated with the ERRAT tool with quality factor score of $>50$, which is accepted as high quality model [42]. Ramachandran plot identified $80-90 \%$ of modelled proteins residues in the allowed region assuring good quality structure modelling of the target proteins (Table 2). Finally, six (06) proteins were prioritized on the basis of (i) pockdrug probability score 0.5 [30], (ii) ERRAT quality factor $\geq 90$ [28], and (iii) protein-protein interaction node degree i.e. $K \geq 5$ [33] (Table 2; Fig. 2). These six prioritized targets are speculating to hold promising druggable pockets to anchor small drug-like molecules and act as indispensable hub proteins in P. falciparum metabolic network.

\section{Pharmacophore based virtual screening}

Among finally shortlisted targets, the PfAp4AH was prioritized for drug-like compounds virtual screening. The pharmacophore model designed from the three-dimensional structure of ligand binding pocket of PfAp4AH showed seven features, i.e. two hydrogen donors, two hydrogen acceptors, two hydrophobic features, and one aromatic feature shown in Fig. 3A. Top 10 hits acquired from Pharmit resource screening were prioritized based on score and RMSD values (Table 3). These top hits compounds were then docked within the ligand binding pocket of PfAp4AH enzyme to predict their binding conformation. The 3D structure of the PfAp4AH enzyme reported with bound substrate (i.e. ATP) within active-site. The site comprises of seven key residues, i.e. Tyr87, Lys94 Ser135, Pro133, His43, Lys48, and Glu115, responsible for ATP hydrolysis [43]. This

Table 1 The P. falciparum 3D7 essential virulent proteins, non-homolog to human host as well as human gut microbiome proteome

\begin{tabular}{llll}
\hline & Protein accession number & Protein name & Nature of protein \\
\hline 1 & Q9TY99_PLAF7 & knob-associated histidine-rich protein & Virulent \\
2 & Q815P1_PLAF7 & Cell traversal protein for ookinetes and sporozoites & Virulent \\
3 & (CelTOS), putative & 4-methyl-5(B-hydroxyethyl)-thiazol monophosphate & Virulent \\
4 & C6KTB1_PLAF7 & biosynthesis enzyme & Virulent \\
5 & Q816Z5_PLAF7 & Plasmepsin V & Virulent \\
\hline
\end{tabular}


Table 2 Druggability analyses of shortlisted 15 cytoplasmic proteins of P. falciparum 3D7 essential and human host non-homolog proteins

\begin{tabular}{|c|c|c|c|c|c|c|c|c|}
\hline $\begin{array}{l}\text { Uniprot } \\
\text { accession } \\
\text { numbers }\end{array}$ & $\begin{array}{l}\text { PDB homolog } \\
\text { ID's }\end{array}$ & Protein names & $\begin{array}{l}\text { ERRAT } \\
\text { quality } \\
\text { factor }\end{array}$ & $\begin{array}{l}\text { Ramachandran } \\
\text { plot (residues } \\
\text { in favored } \\
\text { region \%) }\end{array}$ & QMEAN > -4 & $\begin{array}{l}\text { Pock drug } \\
\text { score }>0.5 \\
\text { (Residues in } \\
\text { pocket) }\end{array}$ & $\begin{array}{l}\text { Molecular } \\
\text { weight } \\
\text { (Dalton) }\end{array}$ & $\begin{array}{l}\text { Node degree } \\
(\mathrm{K}) \geq 5 \text { (STRING } \\
\text { analysis) }\end{array}$ \\
\hline O97259_PLAF7 & 3fga.1.C & $\begin{array}{l}\text { Serine/threo- } \\
\text { nine-protein } \\
\text { phosphatase }\end{array}$ & 99.3103 & $94.75 \%$ & -2.11 & $0.24(15)$ & $35,765.00$ & 7.45 \\
\hline $\begin{array}{l}\mathrm{COH}^{\mathrm{C}} 4 \mathrm{~F}^{-} \\
\mathrm{PLAF7}^{*}\end{array}$ & 5cfi.1.A & $\begin{array}{l}\text { Bis(5'- } \\
\text { nucleosyl)- } \\
\text { tetraphos- } \\
\text { phatase } \\
\text { [asymmetri- } \\
\text { cal] }\end{array}$ & 96.1832 & $97.20 \%$ & -0.37 & $0.98(8)$ & $17,750.19$ & 6.36 \\
\hline Q813A9_PLAF7 & 4nc6.1.A & $\begin{array}{l}\text { GTPase-activat- } \\
\text { ing protein, } \\
\text { putative }\end{array}$ & 90.2778 & $90.71 \%$ & -3.37 & $0.99(20)$ & $50,301.05$ & 4.36 \\
\hline Q812N2_PLAF7* & 4lac.1.C & $\begin{array}{l}\text { Serine/threo- } \\
\text { nine-protein } \\
\text { phosphatase }\end{array}$ & 93.5484 & $97.54 \%$ & -0.72 & $0.91(14)$ & $36,386.98$ & 6.18 \\
\hline Q81082_PLAF7 & 1ryt.1.A & Rifin & 69.7368 & $93.41 \%$ & -2.95 & $0.32(10)$ & $40,648.33$ & 3.82 \\
\hline Q8IIU3_PLAF7 & 2C90.1.A & $\begin{array}{l}\text { RuvB-like } \\
\text { helicase }\end{array}$ & 88.7505 & $92.14 \%$ & -2.41 & & $53,405.94$ & 7.45 \\
\hline Q81599_PLAF7* & 2ibj.1.A & $\begin{array}{l}\text { Cytochrome } \\
\text { b5, putative }\end{array}$ & 94.5205 & $95.00 \%$ & -0.14 & $1(19)$ & $18,244.08$ & 6.55 \\
\hline Q8IDG3_PLAF7 & 6muw.1.C & $\begin{array}{l}\text { Proteasome } \\
\text { subunit alpha } \\
\text { type }\end{array}$ & 92.2727 & $93.72 \%$ & -1.63 & & $27,947.73$ & 10 \\
\hline $\begin{array}{l}\text { Q8IM27- } \\
\text { PLAF7* }^{*}\end{array}$ & 2a22.2.A & $\begin{array}{l}\text { Vacuolar pro- } \\
\text { tein sorting- } \\
\text { associated } \\
\text { protein } 29\end{array}$ & 92.3977 & $95.63 \%$ & 0.23 & $0.96(16)$ & $21,774.02$ & 5.09 \\
\hline $\begin{array}{l}\text { Q8IM19 } \\
\text { PLAF7* }^{*}\end{array}$ & $6 \mathrm{k} 0 \times 1 . \mathrm{B}$ & $\begin{array}{l}\text { Multifunctional } \\
\text { methyltrans- } \\
\text { ferase subunit } \\
\text { TRM112, } \\
\text { putative }\end{array}$ & 92.233 & $91.80 \%$ & -1.87 & $1(10)$ & $14,234.31$ & 8.18 \\
\hline Q8ILZ5_PLAF7 & 6y4l.1.A & $\begin{array}{l}\text { ER membrane } \\
\text { protein } \\
\text { complex } \\
\text { subunit } 2\end{array}$ & 100 & $95.92 \%$ & -2.03 & $0.97(16)$ & $34,952.82$ & 4.36 \\
\hline C6S312_PLAF7 & 6t69.1.A & $\begin{array}{l}\text { MORN repeat- } \\
\text { containing } \\
\text { protein } 5\end{array}$ & 68.3333 & $87.14 \%$ & -0.84 & $0.98(12)$ & $17,938.95$ & 1.33 \\
\hline Q8IKK5_PLAF7 & 1w98.1.B & $\begin{array}{l}\text { Mediator } \\
\text { of RNA } \\
\text { polymerase II } \\
\text { transcription } \\
\text { subunit 20, } \\
\text { putative }\end{array}$ & 88.6179 & $93.80 \%$ & -3.17 & $0.99(11)$ & $36,709.76$ & \\
\hline Q8IKC5_PLAF7 & 4|02.1.A & $\begin{array}{l}\text { Diacylglycerol } \\
\text { kinase }\end{array}$ & 85.8025 & $81.58 \%$ & -8.09 & $0.98(32)$ & $57,642.42$ & 7.09 \\
\hline Q8ID85_PLAF7* & 4ww4.1.B & $\begin{array}{l}\text { RuvB-like } \\
\text { helicase }\end{array}$ & 91.3242 & $94.46 \%$ & -1.49 & $1(14)$ & $54,629.36$ & 7.27 \\
\hline
\end{tabular}

The steric* indicates shortlisted 06 best druggable targets

active-site was utilized in the current study for pharmacophore-based virtual screening. The three key residues of this active-site, i.e. Tyr87, Glu115, and Pro133 are found to primarily engage with the binding of top hit compound (i.e. MolPort-045-917-542) (Fig. 3B). The conserved Glu115 residue is reported as especially 
A

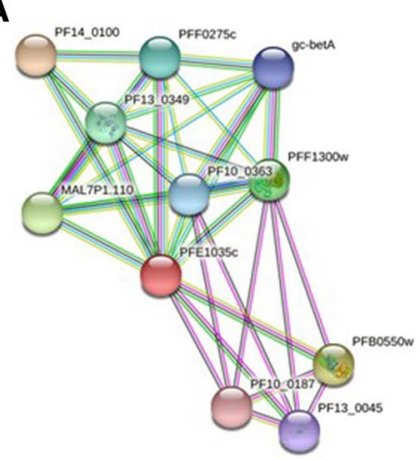

D

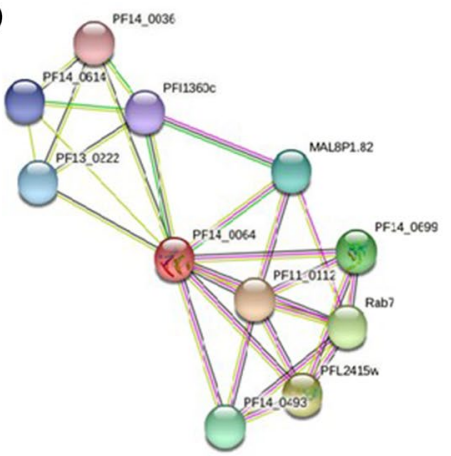

B

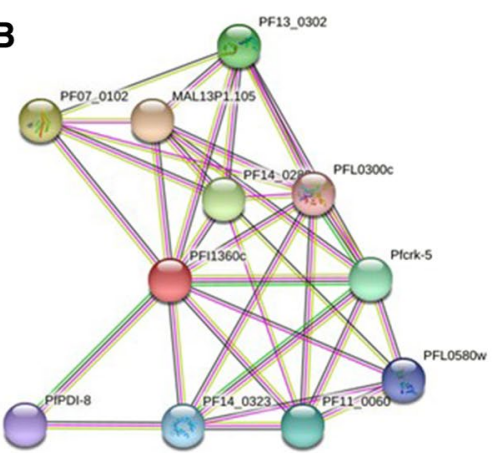

E

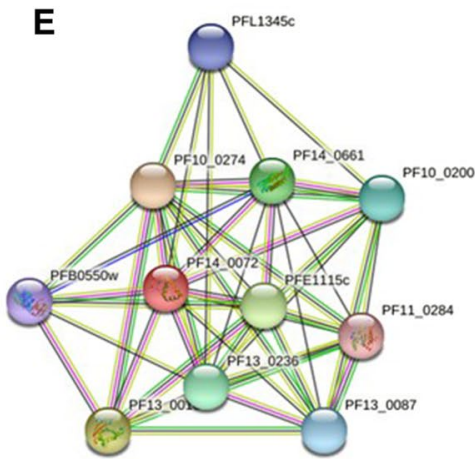

C

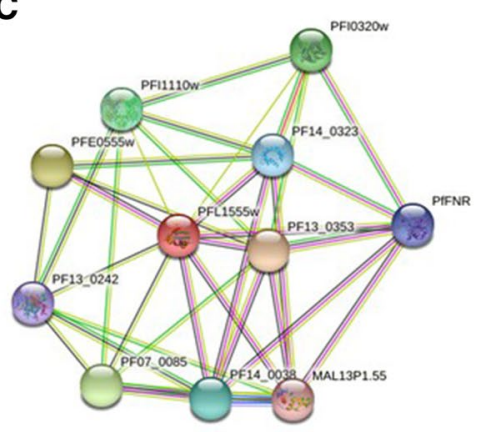

F

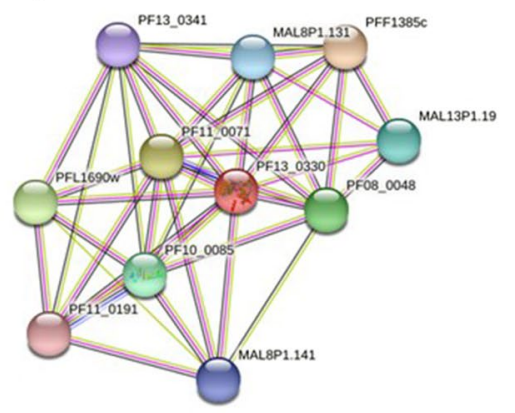

Fig. 2 Protein-protein interaction plots of best interacting proteins. The red colour indicates query protein. A Bis(5'-nucleosyl)-tetraphosphat ase. B Serine/threonine-protein phosphatase. C Cytochrome b5, putative. D Vacuolar protein sorting-associated protein 29. E Multifunctional methyltransferase subunit TRM112, putative. F RuvB-like helicase. All these proteins showed vital interaction with other P. falciparum proteins

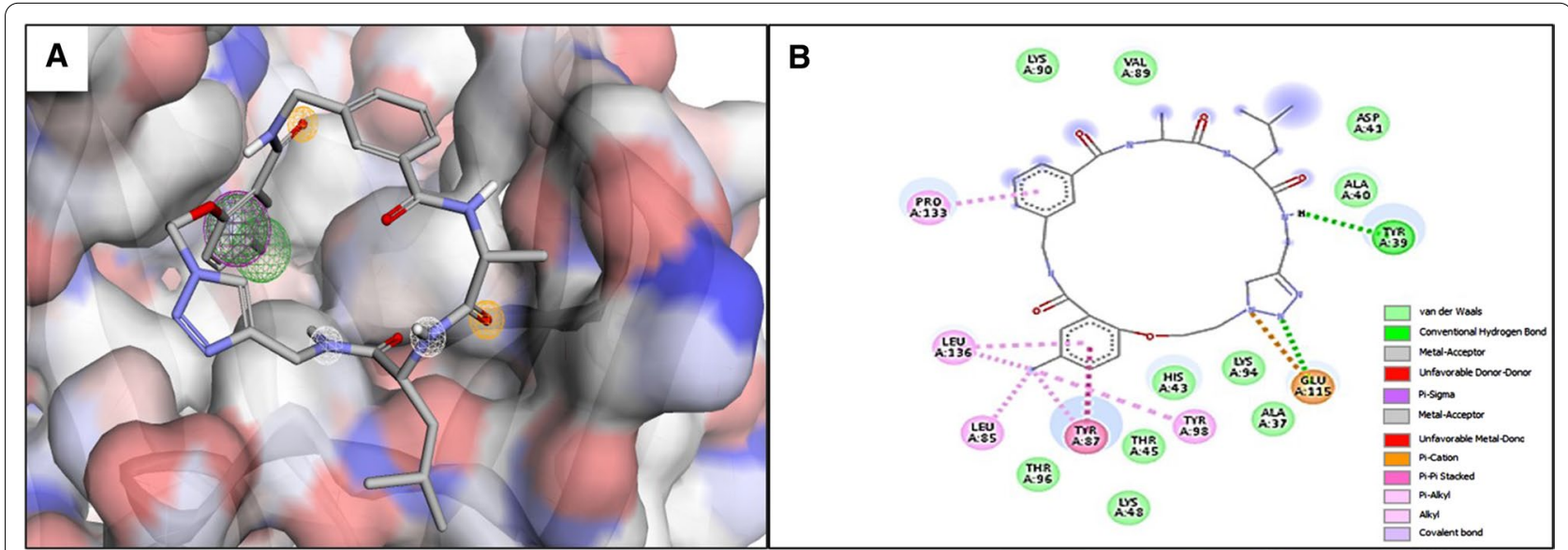

Fig. 3 A Pharmacophore model designed based on the active site of the PfAp4AH enzyme. The features indicated with different colours. Hydrogen-bond donor (white), hydrogen acceptor (yellow), hydrophobic features (green) and aromatic (pink) (B) The molecular interactions of top compound docked within the substrate binding site of PfAp4AH. The nature of protein-ligand interactions shown with different colours legends

important for hydrolysis reaction of PfAp4AH [43]. Besides, the docking analyses predicted that all the top screened compounds explicitly anchor to this active site.

\section{Discussion}

In the current study, the 3380 essentially reported proteins of $P$. falciparum strain 3D7 were analysed to address potent novel druggable targets. These proteins were analysed 
Table 3 The top 10 best docked compounds of Pharmit resource ranked based on the CB-dock score, Pharmit score and RMSD values

\begin{tabular}{|c|c|c|c|c|c|}
\hline $\begin{array}{l}\text { Docked } \\
\text { ligand }\end{array}$ & Pharmit IDs & Chemical structure & CB-Dock score & Pharmit score & RMSD value \\
\hline 1 & MolPort-045-917-542 & & -10.6 & -8.53 & 2.8 \\
\hline 2 & MolPort-045-918-058 & & -8.1 & -8.02 & 2.6 \\
\hline 3 & MolPort-045-931-878 & & -8.4 & -6.98 & 2.5 \\
\hline 4 & MolPort-045-915-346 & & -9.2 & -6.90 & 2.9 \\
\hline 5 & MolPort-045-934-296 & & -8.4 & -6.75 & 2.9 \\
\hline 6 & MolPort-035-379-921 & & -8.2 & -6.66 & 2.7 \\
\hline 7 & MolPort-046-894-718 & & -7.5 & -6.66 & 2.6 \\
\hline
\end{tabular}


Table 3 (continued)

\begin{tabular}{llll}
\hline $\begin{array}{l}\text { Docked } \\
\text { ligand }\end{array}$ & CB-Dock score & Pharmit score RMSD value \\
\hline 8 & MolPort-045-918-093
\end{tabular}

based on their non-homology with the human host as well as human gut microbiome proteome. The targets were additionally shortlisted based on strict threshold criteria of basic druggability features. Among the shortlisted targets (Table 2), the protein, Bis(5'-nucleosyl)-tetraphosphatase (asymmetrical) (COH4F3_PLAF7) also known as asymmetrical diadenosine $5^{\prime}, 5^{\prime \prime}$-P1,P4-tetraphosphate hydrolase (PfAp4A) (EC 3.6.1.17) enzyme participates in pyrimidine and purine metabolism [44, 45]. The PfAp4A hydrolase exhibited high-temperature stability even at $60^{\circ} \mathrm{C}$ [46]. Previously in few studies, the PfAp4A is also tested as a potential drug target against $P$. falciparum $[47,48]$.

The protein serine/threonine-protein phosphatase (Q8I2N2_PLAF7) was also found among finally shortlisted target that involve in regulation of many cellular signaling pathways by catalysing the removal of phosphate group from target enzymes. This enzyme plays a central role in the functional regulation and control of different genes related to the cell cycle [49]. The phosphorylation regulates several primary steps in $P$. falciparum's diverse life cycles. Many of the kinases and phosphatases as well as their substrates are specific to parasites, making eventually the phosphorylation event as a viable target for anti-parasitic action [50]. The protein phosphatase-1, a type of PfPP, involve in the mitotic division of $P$. falciparum and plays an important role in the liberation of merozoites. Prior studies on $P$. falciparum revealed that the activity of PfPP1 is more important as compared to protein phosphatase 2A (PP2A) [51].
This also verified by transcriptomic analysis, where the PfPP1 transcript levels reported higher than PP2A after $24 \mathrm{~h}$ of RBC infection [52]. The okadaic acid (OA), a toxin initially isolated from a marine sponge, i.e. Halichondria okadai has been identified as a selective inhibitor of serine/threonine protein phosphatases (PPPs) and reported to strongly inhibits the PP1, 2A, and $2 \mathrm{~B}$ in-vitro [53]. Out of 30 examined protein phosphatase, the 16 protein phosphatases along with PP1 and putative phosphatases seem to be important for blood-stage parasites [51]. Moreover, some studies also showed that PfPP1 is indispensable for blood-stage parasite survival [54]. Many phosphatases play key roles in the pathological pathways, and their inactivation may help to prevent or postpone the emergence of human diseases. Therefore, the potent inhibitors for such phosphatases might be of great therapeutic benefit.

The enzyme cytochrome b5 Reductase (cb5r) (Q8I599_ PLAF7) plays a role in fatty acid elongation, cholesterol biosynthesis, and cytochrome P450-mediated detoxification of xenobiotics [55]. This protein has been thoroughly studied in mammals, but still needs to be characterized in microorganisms, such as fungi and parasites, including $P$. falciparum. There is a close phylogenetic relationship between the plant and $P$. falciparum cb5r proteins. The plant $c b 5 r$ has been identified as a novel herbicidal target [55]. This protein reported essential for $P$. falciparum survival and was found human host non-homolog and possibly be a potent 
therapeutic target, thereby might be a worthy candidate for drug development against malaria.

The vacuolar protein sorting-associated protein 29 (VPS29) (Q8IM27_PLAF7) is involved in the essential metabolic process of proteins translocation to the subcellular organelles. The $P$. falciparum sort and traffic newly synthesized proteins to target intracellular organelles as well as beyond the plasma membrane into the host cell in some cases [56]. The P. falciparum VPS29 (i.e. PfVPS29) is the functional component in the assembly of the retromer complex [57]. During the PPI analysis, the pfVPS29 showed direct interactions with other retromer complex components i.e. PfVPS26, VPS9, VPS10 as shown in Fig. 2. The PfVPS29 is located in the cytosol and highly expressed in early trophozoite and schizont stages [58]. Inhibiting the activity of PfVPS29 may lead to the disassembling of the retromer complex and possibly halt the protein sorting function of the $P$. falciparum.

The multifunctional methyltransferase subunit (Q8IM19_PLAF7) have methyltransferase activity during post-translational modifications, chromatin remodeling and protein heterodimerization activity [44]. The protein methyltransferases (PMTs) have been linked to the pathogenesis of a variety of diseases, including human cancers, inflammatory diseases, metabolic diseases, and neurodegenerative diseases. The PMTs are highly attractive among the histone-modifying enzymes and act as drug targets $[59,60]$. However, to date no study been conducted about the inhibition of $P$. falciparum methyltransferase.

The RuvB-like helicase (Q8ID85_PLAF7) also shortlisted as therapeutic target in the current study. The RuvB-like helicase function like ATP- dependent helicases. It has a vital role in the cell cycle and transcription [61-63]. The RUVBL proteins (RUVBL1 \& 2) are known to regulate various essential cellular processes in different organisms like Saccharomyces cerevisiae, Drosophila melanogaster and Caenorhabditis elegans [64-66]. Three types of RuvB, i.e., PfRuvB1, PfRuvB2, and PfRuvB3 are present in the P. falciparum. The PfRuvB1 possesses ssDNA-stimulated ATPase activity and function as a helicase that unwind the DNA in a 5' to 3' direction [62]. The PfRuvB2 function similar to PfRuvB1, however, its helicase activity is comparatively weak. The PfRuvB3 function only as ATPase with no helicase activity during schizont/merozoits or interaerythocytic mitosis [67]. During the developmental stages of the parasite, the PfRuvB1 and PfRuvB2 are expressed in the asexual phase, while the PfRuvB3 expresses only during the schizont stage, where intraerythrocytic mitosis of $P$. falciparum occurs [68]. The PfRvuBL3 protein is a true homolog of yeast RuvBL2. Since in yeast, the RuvBL proteins are found extremely indispensable for survival and known to regulate the transcription of almost $5 \%$ of yeast genes [64]. The RuvB- like helicases are suitable drug targets to control malaria due to their essentiality for pathogen and non-homology with human host proteome. It is reported that helicases are required for the proliferation of bacteria, viruses and Plasmodium, and inhibiting the DNA unwinding activity reduces the replication of these pathogens in cell cultures and animal models [69-71]. The PfRuvB1 ATPase activity is formerly reported to be inhibited by actinomycin, novobiocin, and ethidium bromide [72].

Among the shortlisted targets, the refined 3D structure of PfAp4AH is available in PDB. It was, therefore, prioritized for drug-like compounds screening based on in silico drug discovery approaches to address potent inhibitors. The PfAp4AH enzyme regulates the levels of signaling molecules, i.e. diadenosine tetraphosphate (Ap4A) by hydrolyzing it to ATP and AMP. This enzyme is localized at the infected $\mathrm{RBC}$ membrane in the subpopulation of infected cells [43]. The Ap4A and Ap5A molecules are the chief substrates of PfAp4AH enzyme and key mediators of cellular communication and function through purinergic receptors [73]. Hence, signaling mediated by these molecules within RBCs is of special interest in malaria [74]. The purinergic signaling event is reported to play an important role in parasite invasion [75]. Limited or no comprehensive studies are available about the PfAp4AH inhibition and drug-like compound screening [74]. However, this target been considered worthy for drug discovery and inhibition in other species, such as Mycobacterium tuberculosis [76].

\section{Conclusion}

The recently published essential proteins of $P$. falciparum were utilized and the comparative proteomics analyses along with in silico druggability approaches were employed to identify novel and suitable drug targets against $P$. falciparum. The study based on comparative sequence analysis, updated biological databases scanning and multi-direction druggability analyses. This ultimately prioritized and addressed several novel druggable targets against $P$. falciparum infection not highlighted before. The drug targets and the drug-like compounds prioritized in the current study would be worthy to devise new strategies to combat the $P$. falciparum drug resistance issues.

\section{Abbreviations \\ WHO: World Health Organization; PfCRT: Plasmodium falciparum Chloroquine resistant transporter; Pfk13 gene: Plasmodium falciparum Kelch-13 gene; BLAST: Basic Local Alignment Search Tool; Ap4AH: Diadenosine tetraphos- phate Hydrolase; PDB: Protein Data Bank; PfPP: Plasmodium falciparum Protein phosphatase.}

\section{Supplementary Information}

The online version contains supplementary material available at https://doi. org/10.1186/s12936-021-03865-1. 
Additional file 1: Plasmodium falciparum strain 3D7 non paralogous essential proteins.

Additional file 2 : Plasmodium falciparum strain 3D7 proteins, nonhomologous to human as well as human's gut flora proteins.

Additional file $\mathbf{3}$ : Plasmodium falciparum 3D7 essential proteins homologs to human gut microbiome proteome.

Additional file 4: The approved antimalarial targets obtained from Alexander, S. P., et al. (2019) [77]. The accession IDs in Bold show approved antimalarial targets recovered in the list of 183 prioritized targets (Table S2), while accession IDs in italic and asterisk* are approved targets recovered by relaxing the human microbiome database screening criteria to $35 \%$ sequence identity and query coverage.

\section{Acknowledgements}

Not applicable.

\section{Authors' contributions}

AK and FA conceived the basic idea. The FA, HW, SJ and AZ performed the analysis and prepared the initial draft. MA, IA, SS and SGA reviewed the critical analysis and helped in draft preparation. AK finalized the draft and supervised the overall study. All authors have read and agreed to the published version of the manuscript. All authors read and approved the final manuscript.

\section{Funding}

Not applicable.

\section{Availability of data and materials}

The supplementary data relevant to this study is provided.

\section{Declarations}

\section{Ethics approval and consent to participate}

Not applicable.

\section{Consent for publication}

All authors read and agreed to publish the study.

\section{Competing interests}

The authors declare that they have no competing interests.

\section{Author details}

'Department of Biochemistry, Abdul Wali Khan University Mardan, Mardan 23200, Pakistan. ${ }^{2}$ Department of Biochemistry, Hazara University, Mansehra 21120, Pakistan.

Received: 31 March 2021 Accepted: 25 July 2021

Published online: 03 August 2021

\section{References}

1. Bakhraibah AO. Malaria in modern day: a review article. Austr J Basic Appl Sci. 2018;12:73-5.

2. Rich S, Leendertz FH, Xu G. LeBreton M, Djoko CF, Aminake MN, et al The origin of malignant malaria. Proc Natl Acad Sci USA. 2009;106:14902-7.

3. Perkins DJ, Were T, Davenport GC, Kempaiah P, Hittner JB, Ong'echa JM. Severe malarial anemia: innate immunity and pathogenesis. Int J Biol Sci. 2011;7:1427.

4. Perlmann P, Troye-Blomberg M. Malaria blood-stage infection and its control by the immune system. Folia Biol (Praha). 2000;46:210-8.

5. Baingana FK, Bos ER. Changing patterns of disease and mortality in SubSaharan Africa: an overview. In: Jamison DT, Feachem RG, et al., editors. Disease and mortality in sub-Saharan Africa. 2nd ed. Washington: International Bank for Reconstruction and Development, The World Bank; 2006

6. WHO. World malaria report. 20 years of global progress and challenges. Geneva: World Health Organization; 2020. p. 2020.
7. Bhatia R, Rastogi RM, Ortega L. Malaria successes and challenges in Asia. J Vector Borne Dis. 2013;50:239-47.

8. Zuber JA, Takala-Harrison S. Multidrug-resistant malaria and the impact of mass drug administration. Infect Drug Resist. 2018;11:299-306.

9. Lim P, Chy S, Ariey F, Incardona S, Chim P, Sem R, et al. Pfert polymorphism and chloroquine resistance in Plasmodium falciparum strains isolated in Cambodia. Antimicrob Agents Chemother. 2003:47:87-94.

10. Trape JF. The public health impact of chloroquine resistance in Africa. Am J Trop Med Hyg. 2001;64((1_Suppl)):12-7.

11. Hyde JE. Drug-resistant malaria-an insight. FEBS J. 2007;274:4688-98.

12. Dondorp AM, Nosten F, Yi P, Das D, Phyo AP, Tarning J, et al. Artemisinin resistance in Plasmodium falciparum malaria. N Engl J Med. 2009:361:455-67.

13. Noedl H, Se Y, Schaecher K, Smith BL, Socheat D, Fukuda MM. Evidence of artemisinin-resistant malaria in western Cambodia. N Engl J Med. 2008;359:2619-20.

14. Ouji M, Augereau J-M, Paloque L, Benoit-Vical F. Plasmodium falciparum resistance to artemisinin-based combination therapies: a sword of Damocles in the path toward malaria elimination. Parasite. 2018;25:24.

15. Dong Y, Wang J, Sun A, Deng Y, Chen M, Xu Y, et al. Genetic association between the Pfk13 gene mutation and artemisinin resistance phenotype in Plasmodium falciparum isolates from Yunnan Province. China Malar J. 2018;17:478.

16. Zhang M, Wang C, Otto TD, Oberstaller J, Liao X, Adapa SR, et al. Uncovering the essential genes of the human malaria parasite Plasmodium falciparum by saturation mutagenesis. Science. 2018;360:eaap7847.

17. Bushell E, Gomes AR, Sanderson T, Anar B, Girling G, Herd C, et al. Functional profiling of a Plasmodium genome reveals an abundance of essential genes. Cell. 2017;170:260-72.

18. Huang Y, Niu B, Gao Y, Fu L, Li W. CD-HIT Suite: a web server for clustering and comparing biological sequences. Bioinformatics. 2010;26:680-2.

19. Johnson M, Zaretskaya I, Raytselis Y, Merezhuk Y, McGinnis S, Madden TL. NCBI BLAST: a better web interface. Nucleic Acids Res. 2008;36((suppl_2)):W5-9.

20. Mukherjee S, Gangopadhyay K, Mukherjee SB. Identification of potential new vaccine candidates in Salmonella typhi using reverse vaccinology and subtractive genomics-based approach. bioRxiv. 2020. https://doi.org/ $10.1101 / 521518$

21. Hasan MA, Khan MA, Sharmin T, Mazumder MHH, Chowdhury AS. Identification of putative drug targets in Vancomycin-resistant Staphylococcus aureus (VRSA) using computer aided protein data analysis. Gene. 2016:575:132-43.

22. Aslam M, Shehroz M, Shah M, Khan MA, Afridi SG, Khan A. Potential druggable proteins and chimeric vaccine construct prioritization against Brucella melitensis from species core genome data. Genomics. 2020:112:1734-45.

23. Sayers S, Li L, Ong E, Deng S, Fu G, Lin Y, et al. Victors: a web-based knowledge base of virulence factors in human and animal pathogens. Nucleic Acids Res. 2019;47:D693-700.

24. Wishart DS, Feunang YD, Guo AC, Lo EJ, Marcu A, Grant JR, et al. DrugBank 5.0: a major update to the DrugBank database for 2018. Nucleic Acids Res. 2018;46:D1074-82.

25. Berman HM, Battistuz T, Bhat TN, Bluhm WF, Bourne PE, Burkhardt K, et al. The protein data bank. Acta Crystallogr D Biol Crystallogr. 2002;58:899-907.

26. Uddin $\mathrm{R}$, Jamil F. Prioritization of potential drug targets against $P$. aeruginosa by core proteomic analysis using computational subtractive genomics and Protein-Protein interaction network. Comput Biol Chem. 2018;74:115-22.

27. Waterhouse A, Bertoni M, Bienert S, Studer G, Tauriello G, Gumienny $R$, et al. SWISS-MODEL: homology modelling of protein structures and complexes. Nucleic Acids Res. 2018;46:W296-303.

28. Dym O, Eisenberg D, Yeates T. ERRAT: Detection of errors in protein models. Int Tables Crystallogr. 2012. https://doi.org/10.1107/9780955360 2060000881.

29. Kleywegt GJ. Jones TA. Phi/psi-chology: Ramachandran revisited. Structure. 1996:4:1395-400.

30. Hussein HA, Borrel A, Geneix C, Petitjean M, Regad L, Camproux A-C. PockDrug-Server: a new web server for predicting pocket druggability on holo and apo proteins. Nucleic Acids Res. 2015;43:W436-42. 
31. Yu CS, Chen YC, Lu CH, Hwang JK. Prediction of protein subcellular localization. Proteins. 2006;64:643-51.

32. Artimo P, Jonnalagedda M, Arnold K, Baratin D, Csardi G, De Castro E, et al. ExPASy: SIB bioinformatics resource portal. Nucleic Acids Res. 2012;40:W597-603.

33. Mering CV, Huynen M, Jaeggi D, Schmidt S, Bork P, Snel B. STRING: a database of predicted functional associations between proteins. Nucleic Acids Res. 2003;31:258-61.

34. Sunseri J, Koes DR. Pharmit: interactive exploration of chemical space. Nucleic Acids Res. 2016;44:W442-8.

35. Liu Y, Grimm M, Dai W, Hou M, Xiao ZX, Cao Y. CB-Dock: a web server for cavity detection-guided protein-ligand blind docking. Acta Pharmacol Sinica. 2020;41:138-44.

36. Discovery Studio Visualizer Software Version 4.0. 2012. http://www.accelrys. com.

37. Oberstaller J, Otto TD, Rayner JC, Adams JH. Essential genes of the parasitic Apicomplexa. Trends Parasitol. 2021;37:304-16.

38. Rowland I, Gibson G, Heinken A, Scott K, Swann J, Thiele I, et al. Gut microbiota functions: metabolism of nutrients and other food components. Eur J Nutr. 2018:57:1-24.

39. Yamashiro Y. Gut microbiota in health and disease. Ann Nutr Metabol. 2017;71:242-6.

40. Solanki V, Tiwari V. Subtractive proteomics to identify novel drug targets and reverse vaccinology for the development of chimeric vaccine against Acinetobacter baumannii. Sci Rep. 2018;8:9044.

41. Hadizadeh M, Tabatabaiepour SN, Tabatabaiepour SZ, Hosseini Nave H, Mohammadi M, Sohrabi SM. Genome-wide identification of potential drug target in enterobacteriaceae family: a homology-based method. Microb Drug Resist. 2018;24:8-17.

42. Messaoudi A, Belguith $H$, Hamida JB. Homology modeling and virtual screening approaches to identify potent inhibitors of VEB-1 $\beta$-lactamase. Theor Biol Med Model. 2013;10:22.

43. Sharma A, Yogavel M, Sharma A. Structural and functional attributes of malaria parasite diadenosine tetraphosphate hydrolase. Sci Rep. 2016;6:19981.

44. Gaudet P, Livstone MS, Lewis SE, Thomas PD. Phylogenetic-based propagation of functional annotations within the Gene Ontology consortium. Brief Bioinforma. 2011:12:449-62.

45. Guranowski A, Jakubowski H, Holler E. Catabolism of diadenosine 5', 5 '--P1, P4-tetraphosphate in procaryotes Purification and properties of diadenosine 5', 5'"-P1, P4-tetraphosphate (symmetrical) pyrophosphohydrolase from Escherichia coli K12. J Biol Chem. 1983;258:14784-9.

46. Osman W, Endo S, Oh-Hashi K, Kitamura Y, Kitade Y. Molecular characterization and mutational analysis of recombinant diadenosine 5', $5^{\prime \prime}-\mathrm{P} 1$, P4-tetraphosphate hydrolase from Plasmodium falciparum. Biol Pharm Bull. 2012;35:1191-6.

47. Guranowski A, Starzyńska E, Pietrowska-Borek M, Rejman D, Blackburn GM. Novel diadenosine polyphosphate analogs with oxymethylene bridges replacing oxygen in the polyphosphate chain: potential substrates and/or inhibitors of Ap4A hydrolases. FEBS J. 2009:276:1546-53.

48. Guranowski A, Starzyska E, McLennan AG, Baraniak J, Stec WJ. Adenosine5'-O-phosphorylated and adenosine-5'-O-phosphorothioylated polyols as strong inhibitors of (symmetrical) and (asymmetrical) dinucleoside tetraphosphatases. Biochem J. 2003;373:635-40.

49. Shi Y. Serine/threonine phosphatases: mechanism through structure. Cell. 2009;139:468-84

50. Yang C, Arrizabalaga G. The serine/threonine phosphatases of apicomplexan parasites. Mol Microbiol. 2017;106:1-21.

51. Yokoyama D, Saito-Ito A, Asao N, Tanabe K, Yamamoto M, Matsumura T. Modulation of the Growth of Plasmodium falciparum in Vitroby protein serine/threonine phosphatase inhibitors. Biochem Biophys Res Commun. 1998;247:18-23.

52. Khalife J, Pierrot C. Phosphatases are emerging as novel druggable targets in Plasmodium. Future Microbiol. 2016;11:603-6.

53. Dounay A, Forsyth C. Okadaic acid: the archetypal serine/threonine protein phosphatase inhibitor. Curr Med Chem. 2002;9:1939-80.

54. Zhang M, Mishra S, Sakthivel R, Fontoura BM, Nussenzweig V. UIS2: a unique phosphatase required for the development of Plasmodium liver stages. PLoS Pathog. 2016;12:e1005370.
55. Malvisi L. Functional characterization of cytochrome b5 reductase and its electron acceptor cytochrome b5 in Plasmodium falciparum. Dissertation, University of South Florida; 2009.

56. Maier AG, Cooke BM, Cowman AF, Tilley L. Malaria parasite proteins that remodel the host erythrocyte. Nat Rev Microbiol. 2009;7:341-54.

57. Iqbal MS, Siddiqui AA, Banerjee C, Nag S, Mazumder S, De R, et al. Detection of retromer assembly in Plasmodium falciparum by immunosensing coupled to Surface Plasmon Resonance. Biochim Biophys Acta Proteins Proteom. 2018;1866:722-30.

58. I lqbal MS, Siddiqui AA, Alam A, Goyal M, Banerjee C, Sarkar S, et al. Expression, purification and characterization of Plasmodium falciparum vacuolar protein sorting 29. Protein Expr Purif. 2016;120:7-15.

59. Copeland RA, Solomon ME, Richon VM. Protein methyltransferases as a target class for drug discovery. Nat Rev Drug Discov. 2009;8:724-32.

60. Brecher M, Chen H, Liu B, Banavali NK, Jones SA, Zhang J, et al. Novel broad spectrum inhibitors targeting the flavivirus methyltransferase. PLoS ONE. 2015;10:0130062.

61. Ahmad M, Tuteja R. Plasmodium falciparum RuvB proteins: emerging importance and expectations beyond cell cycle progression. Commun Integr Biol. 2012;5:350-61.

62. Ahmad M, Tuteja R. Plasmodium falciparum RuvB1 is an active DNA helicase and translocates in the $5^{\prime}-3^{\prime}$ direction. Gene. 2013;515:99-109.

63. Jha S, Dutta A. RVB1/RVB2: running rings around molecular biology. Mol Cell. 2009:34:521-33.

64. Qiu X-B, Lin Y-L, Thome KC, Pian P, Schlegel BP, Weremowicz S, et al. An eukaryotic RuvB-like protein (RUVBL1) essential for growth. J Biol Chem. 1998:273:27786-93.

65. Bauer A, Chauvet S, Huber O, Usseglio F, Rothbächer U, Aragnol D, et al. Pontin52 and Reptin52 function as antagonistic regulators of $\beta$-catenin signalling activity. EMBO J. 2000;19:6121-30.

66. Matias PM, Gorynia S, Donner P, Carrondo MA. Crystal structure of the human AAA+ protein RuvBL1. J Biol Chem. 2006;281:38918-29.

67. Ahmad M, Tuteja R. Plasmodium falciparum RuvB2 translocates in $5^{\prime}-3^{\prime}$ direction, relocalizes during schizont stage and its enzymatic activities are up regulated by RuvB3 of the same complex. Biochim Biophys Acta Proteins Proteom. 2013;1834:2795-811.

68. Ahmad M, Singh S, Afrin F, Tuteja R. Novel RuvB nuclear ATPase is specific to intraerythrocytic mitosis during schizogony of Plasmodium falciparum. Mol Biochem Parasitol. 2012;185:58-65

69. Borowski P, Lang M, Haag A, Schmitz H, Choe J, Chen H-M, et al. Characterization of imidazo[4, 5-d]pyridazine nucleosides as modulators of unwinding reaction mediated by West Nile virus nucleoside triphosphatase/ helicase: evidence for activity on the level of substrate and/or enzyme. Antimicrob Agents Chemother. 2002;46:1231-9.

70. Frick DN. Helicases as antiviral drug targets. Drug News Perspect. 2003;16:355-62.

71. Tuteja R. Helicases - feasible antimalarial drug target for Plasmodium falciparum. FEBS J. 2007;274:4699-704.

72. Ahmad M, Tarique M, Afrin F, Tuteja N, Tuteja R. Identification of inhibitors of Plasmodium falciparum RuvB1 helicase using biochemical assays. Protoplasma. 2015:252:117-25.

73. McLennan A. The Nudix hydrolase superfamily. Cell Mol Life Sci. 2006:63:123-43

74. Mildvan A, Xia Z, Azurmendi H, Saraswat V, Legler P, Massiah M, et al. Structures and mechanisms of Nudix hydrolases. Arch Biochem Biophys. 2005:433:129-43.

75. Levano-Garcia J, Dluzewski AR, Markus RP, Garcia CRS. Purinergic signalling is involved in the malaria parasite Plasmodium falciparum invasion to red blood cells. Purinergic Signal. 2010;6:365-72.

76. Branson KM, Mertens HD, Swarbrick JD, Fletcher Jl, Kedzierski L, Gayler KR, et al. Discovery of inhibitors of lupin diadenosine 5 tetraphosphate hydrolase by virtual screening ', 5'I'-P 1, P 4. Biochemistry. 2009;48:7614-20.

77. Alexander SP, Kelly E, Mathie A, Peters JA, Veale EL, Armstrong JF, et al. The concise guide to pharmacology 2019/20: introduction and other protein targets. Br J Pharmacol. 2019;176:S1-20.

\section{Publisher's Note}

Springer Nature remains neutral with regard to jurisdictional claims in published maps and institutional affiliations. 